20

\title{
Спектры кругового дихроизма дисперсий и текстуры фаз ДНК
}

\author{
(С) Ю.М. Евдокимов ${ }^{1}$, С.Г. Скуридин ${ }^{1}$, В.И. Салянов ${ }^{1}$, О.Н. Компанец ${ }^{2}$, Е.И. Кац ${ }^{3}$ \\ ${ }^{1}$ Институт молекулярной биологии им. В.А. Энгельгардта РАН, \\ 119991 Москва, Россия \\ ${ }^{2}$ Институт спектроскопии РАН, \\ 108840 Москва, Троицк, Россия \\ ${ }^{3}$ Институт теоретической физики им. Л.Д. Ландау РАН, \\ 119334 Москва, Россия \\ e-mail: yevdokim@eimb.ru
}

Поступила в редакцию 23.05.2018 г.

В окончательной редакции 22.08.2018 г.

Изучены спектры кругового дихроизма (КД) жидкокристаллических дисперсий, сформированных в результате фазового исключения двухцепочечных молекул ДНК из водно-солевых растворов полиэтиленгликоля, при комнатной и повышенных температурах. Спектры КД позволяют отличать дисперсии, имеющие холестерическую упаковку молекул ДНК, от дисперсий с гексагональной упаковкой этих молекул. При нагревании дисперсий с гексагональной упаковкой ДНК в их спектрах КД возникает аномальная полоса, свидетельствующая о новом фазовом переходе: гексагональная „возвратная“ холестерическая упаковка молекул ДНК в изолированных частицах дисперсий. При комнатной температуре в спектрах таких дисперсий аномальная полоса отсутствует. При концентрировании частиц жидкокристаллических дисперсий ДНК в результате низкоскоростного центрифугирования получены жидкокристаллические фазы ДНК. Изучены текстуры тонких слоев этих фаз. Показано, что способ пространственной упаковки молекул ДНК в единичных частицах дисперсий, образующихся в водно-солевых растворах полиэтиленгликоля, может отличаться от способа упаковки этих молекул в макроскопических фазах.

DOI: $10.21883 /$ OS.2018.12.46950.144-18

\section{Введение}

Известно, что молекулы низкомолекулярных соединений могут при определенных условиях образовывать целый ряд „классических“ жидкокристаллических (ЖК) структур (фаз) [1-3]. Конкретные способы пространственного упорядочения молекул в таких фазах определены в большом числе экспериментальных работ $[4,5]$.

Ответ на вопрос о структуре ЖК фаз полимеров является не таким определенным [6,7]. Например, в этом случае предсказывается появление некоторых новых типов структур фаз, не наблюдаемых в низкомолекулярных системах [8-10]. Ситуация становится еще более неопределенной в случае ЖК фаз биополимеров, в частности, молекул двухцепочечных (ДЦ) нуклеиновых кислот (НК), имеющих, как правило, очень высокую молекулярную массу $\left(>3 \cdot 10^{6} \mathrm{Da}\right)$ [11-13]. Это связано с целым рядом факторов, в частности, с низкой скоростью диффузии этих молекул в фазах, а также специфическими особенностями их вторичной структуры.

Как правило, ЖК фазы линейных ДЦ молекул ДНК получают в результате растворения лиофилизированного препарата НК в небольшом объеме водно-солевого раствора и последующего увеличения концентрации ДЦ ДНК за счет его испарения [14-16] (или повышения осмотического давления раствора за счет диализа $[17,18])$. При низкой концентрации раствор ДЦ ДНК - классическая изотропная жидкость. Когда концентрация ДЦ ДНК в водно-солевом растворе увеличи- вается (или температура раствора уменьшается) раствор становится мутным, что указывает на фазовый переход молекул ДЦ ДНК из изотропного в конденсированное состояние, который в зависимости от молекулярной массы и концентрации ДНК может быть как внутри-, так и межмолекулярным $[19,20]$. Таким образом, при достижении (тем или иным способом) „критической“ концентрации ДЦ ДНК в водно-солевых растворах (при комнатной температуре) спонтанно происходит переход молекул ДНК в конденсированное состояние, который в первом приближении вполне подчиняется правилам, предложенным Л. Онзагером [21].

Образующиеся „классические“ фазы линейных ДЦ ДНК были изучены при помощи разных методов (поляризационная и электронная микроскопия, малоугловое рассеяние рентгеновского излучения (МУР) и др.). Это позволило установить характер упаковки молекул ДЦ ДНК в разных фазах и доказать существование целого каскада фаз, наблюдаемых в случае увеличения концентрации ДЦ ДНК в растворе: изотропная фаза $\rightarrow$ (голубая фаза?) $\rightarrow$ холестерическая фаза $\rightarrow$ гексагональная (колонная) фаза $\rightarrow$ кристаллическая фаза $[12,13,22-25]$. Известно также, что при комнатной температуре наряду с ЖК фазами могут быть получены ЖК дисперсии ДЦ ДНК [26,27]. Эти дисперсии могут быть получены, в частности, в результате фазового исключения линейных молекул ДНК из водно-солевых растворов полиэтиленгликоля (ПЭГ) [28,29] или смеси ПЭГ с минеральным маслом [30]. Дисперсии ДНК формируются в тех случа- 
ях, когда концентрация ПЭГ в растворе, используемом для фазового исключения, превышает „критическое“ значение [28].

Осмотическое давление раствора ПЭГ, определяемое его концентрацией, контролирует характер упаковки соседних, линейных, жестких ДЦ молекул ДНК в частицах дисперсии [29,31]. Центрифугирование дисперсий ДЦ молекул ДНК приводит к седиментации частиц этих дисперсий и формированию осадков (фаз) [28]. Вопрос об упаковке молекул ДЦ ДНК в фазах, полученных таким способом, оставался практически не исследованным [32,33]. Текстуры фаз, полученных в результате такого способа концентрирования частиц дисперсий ДНК, остаются практически не исследованными.

Цель настоящей работы состояла в сопоставлении спектров КД дисперсий ДЦ молекул ДНК, сформированных в ПЭГ-содержащих растворах, с текстурами фаз, полученных в результате седиментации частиц этих дисперсий при их центрифугировании.

\section{Материалы и методы}

Использовали дополнительно очищенный от примесей и деполимеризованный препарат ДЦ ДНК из тимуса телят („Sigma“, США) с молекулярной массой $(0.5-0.8) \cdot 10^{6} \mathrm{Da}$. Молекулярную массу ДНК после очистки и деполимеризации определяли при помощи электрофореза в 1\%-ном агарозном геле. Концентрацию ДНК в водно-солевых растворах определяли спектрофотометрически, пользуясь известным значением молярного коэффициента поглощения $\left(\varepsilon_{258.4}=6600 \mathrm{M}^{-1} \mathrm{~cm}^{-1}\right)$. Препарат ПЭГ („Serva“, Германия; молекулярная масса $4000 \mathrm{Da}$ ) использовали без дополнительной очистки. Исходный водно-солевой раствор ПЭГ (0.3 M NaCl, СПЭГ $=600 \mathrm{mg} / \mathrm{ml}$ ) готовили, растворяя навески $\mathrm{NaCl}$ и ПЭГ в $0.002 \mathrm{M} \mathrm{Na}^{+}$-фосфатном буфере $(\mathrm{pH} \sim 7.0)$.

Дисперсии ДЦ ДНК в водно-солевых растворах с разным содержанием ПЭГ $(120 \mathrm{mg} / \mathrm{ml} \leq \mathrm{CПЭГ} \leq 300 \mathrm{mg} / \mathrm{ml})$ формировали в соответствии с методикой, описанной ранее [28]. Согласно этой методике, равные объемы водносолевых растворов, один из которых содержал ДНК, а другой - ПЭГ (концентрация ДНК и ПЭГ в растворах в два раза превышала требуемые конечные значения), смешивали. Полученную смесь интенсивно встряхивали на вихревом встряхивателе „IKA VORTEX Genius 3“ (Германия) в течение $1 \mathrm{~min}$. После этого полученную смесь выдерживали при комнатной температуре в течение суток для завершения формирования дисперсии ДНК, а затем использовали в работе. Концентрация ДНК в исследованных ПЭГ-содержащих растворах составляла $10-30 \mu \mathrm{g} / \mathrm{ml}$, а максимальная концентрация ПЭГ $300 \mathrm{mg} / \mathrm{ml}$.

Спектры поглощения растворов регистрировали при помощи спектрофотометра Cary 100 Scan („Varian“, США), а спектры КД - при помощи портативного дихрометра СКД-2 (разработка Института спектроскопии
РАН). Спектры КД представляли в виде зависимости разности интенсивности поглощения лево- и правополяризованного света $\left(\Delta A ; \Delta A=\left(A_{L}-A_{R}\right)\right)$ от длины волны [34]. Во всех случаях использовали прямоугольные кварцевые кюветы („Helma“ 100 QS, Германия) с длиной оптического пути $1 \mathrm{~cm}$.

Температуру в терморегулируемом отсеке дихрометра в интервале от 20 до $80^{\circ} \mathrm{C}$ устанавливали при помощи программы „Управление температурой“, входящей в состав программного обеспечения дихрометра СКД-2. После установки необходимого значения температуры кювету, содержащую $2 \mathrm{ml}$ дисперсии ДНК, выдерживали в течение $10 \mathrm{~min}$ в терморегулируемом отсеке и приступали к регистрации спектра КД в интервале длин волн $250-350 \mathrm{~nm}$

Для анализа текстур использовали осадки фаз ( 2-5 mg), полученные в результате низкоскоростного центрифугирования (5000 rev/min, $40 \mathrm{~min}, 4^{\circ} \mathrm{C}$; центрифуга К-23, Германия) частиц дисперсий, сформированных в результате фазового исключения ДЦ молекул ДНК $\left(C_{\text {днк }}=30 \mu \mathrm{g} / \mathrm{ml}\right)$ из растворов с разной концентрацией ПЭГ $(170 \mathrm{mg} / \mathrm{ml} \leq \mathrm{C} П Э Г \leq 300 \mathrm{mg} / \mathrm{ml})$. Оптические текстуры тонких $(20 \mu \mathrm{m})$ слоев полученных фаз ДНК регистрировали в интервале температур от 20 до $80^{\circ} \mathrm{C}$ при помощи поляризационного микроскопа („Sunny Instruments“, Китай). Конфигурация кювет, использованных для проведения микроскопических исследований, и технические особенности их выполнения подробно описаны в работе [35].

\section{Результаты и обсуждение}

На рис. 1 представлен спектр дисперсии, сформированной из линейных ДЦ молекул ДНК при концентрации ПЭГ в водно-солевом растворе $170 \mathrm{mg} / \mathrm{ml}$ (кривая 3). Видно, что в спектре КД присутствует очень интенсивная (аномальная) отрицательная полоса, расположенная в области поглощения азотистых оснований ДНК $(\lambda 270 \mathrm{~nm})$. Следует отметить, что дисперсии ДЦ молекул ДНК, как и ЖК фазы, являются „окрашенными“, поскольку в составе молекул ДНК присутствуют хромофоры (азотистые основания), поглощающие УФ излучение. В этом случае теории [36-40], учитывающие возникновение ,дальнего“ (ориентационного) порядка в расположении хромофоров в результате формирования слоев из хромофоров и спиральную закрутку этих слоев, предсказывают появление аномальной полосы в спектре КД таких спиральных структур. Поэтому аномальная полоса в спектре КД (рис. 1, кривая 3) свидетельствует о холестерической упаковке молекул ДНК в частицах дисперсии. Амплитуда аномальной полосы зависит от концентрации ПЭГ в водно-солевых растворах [28] и характерна для частиц дисперсий ДНК, образующихся при СПЭГ в пределах от 120 до $220 \mathrm{mg} / \mathrm{ml}$ [32].

На рис. 2 показана оптическая текстура тонкого слоя фазы, полученной в результате концентрирования 


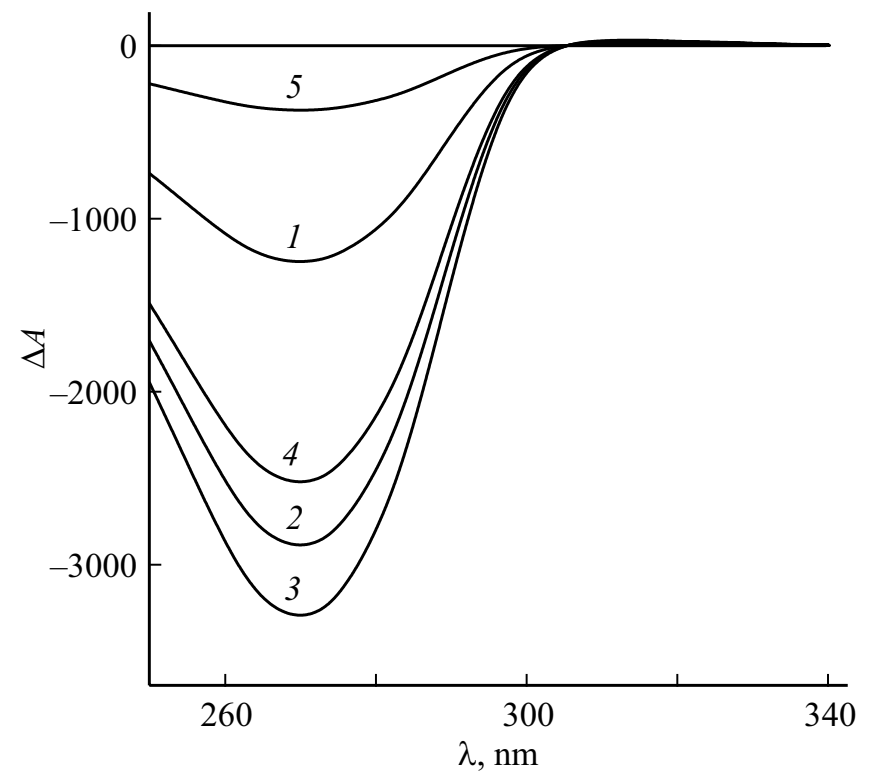

Рис. 1. Спектры КД ЖК дисперсий ДНК, сформированных в водно-солевых растворах с разной концентрацией ПЭГ: $C_{\text {ПэГ }}=120$ (1), 150 (2), 170 (3), 200 (4), $210 \mathrm{mg} / \mathrm{ml}$ (5). $C_{\text {ДнК }}=10 \mu \mathrm{g} / \mathrm{ml}, 0.3 \mathrm{M} \mathrm{NaCl}+0.002 \mathrm{M} \mathrm{Na}^{+}$-фосфатный буфер, $\Delta A=\left(A_{L}-A_{R}\right) \cdot 10^{-6}$ optical units, $L=1 \mathrm{~cm}, T=22^{\circ} \mathrm{C}$.

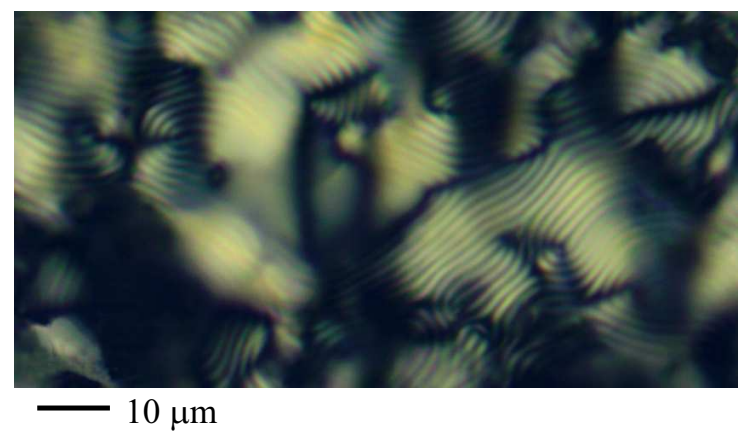

Рис. 2. Текстура „отпечатков пальцев“ холестерической ЖК фазы ДНК, полученной в результате низкоскоростного центрифугирования частиц дисперсии ДНК, сформированной в ПЭГ-содержащем водно-солевом растворе $\left(C_{\text {Пэг }}=170 \mathrm{mg} / \mathrm{ml}\right)$. Масштабная метка на рисунке соответствует $10 \mu \mathrm{m}$.

(осаждения) частиц дисперсии ДНК, сформированной в водно-солевом растворе при СПЭГ $=170 \mathrm{mg} / \mathrm{ml}$. Текстура представляет собой чередование светлых и темных полос и известна под названием текстуры „отпечатков пальцев“ [2,3]. Она наблюдается как при комнатной температуре, так и становится очень заметной при повышении температуры фазы до $40-60^{\circ} \mathrm{C}$. Такая специфическая текстура свидетельствует о холестерической упаковке молекул ДЦ ДНК в фазе, полученной в результате осаждения частиц дисперсии ДНК. Результаты МУР для фаз ДНК, полученных при помощи концентрирования частиц дисперсий в этих условиях [32], также говорят о существовании холестерической упаковки молекул ДНК в этих фазах.

Таким образом, спектры КД, полученные для частиц дисперсий ДНК (рис. 1), и оптическая текстура фазы, сформированной из частиц таких дисперсий (рис. 2), согласуются между собой и подтверждают факт существования холестерической упаковки молекул ДНК как в частицах дисперсии, так и в фазе, образованной при комнатной температуре.

Этот результат может отражать сочетание следующих причин. В результате седиментации происходит локально повышение концентрации (сближение) единичных частиц холестерической дисперсии ДНК, имеющих размер около $500 \mathrm{~nm}$, которые образуют фазу. Хотя в этой фазе пространственная ориентация частиц является первоначально хаотичной, тем не менее, между соседними частицами возникает взаимодействие, которое отсутствовало в случае изолированных частиц. При большом $(\sim 3.5 \mathrm{~nm})$ среднем расстоянии $(d)$ между молекулами ДНК в частицах дисперсии такое взаимодействие оказывает только незначительное влияние на спиральную пространственную упаковку соседних молекул ДНК в частицах, т.е. сохраняется оптически активная, закрученная структура („деформированный“ холестерический жидкий кристалл).

Однако в этих условиях сказывается действие еще одного фактора, а именно достаточно высокой диффузионной подвижности молекул ДНК в пределах единичных частиц дисперсии в водно-солевом растворе ПЭГ $\left(C_{\text {Пэг }}=170 \mathrm{mg} / \mathrm{ml}\right)$. При „удачном“ пространственном расположении соседних частиц дисперсии становится возможным диффузионное „слияние“ молекул ДНК разных частиц, приводящее к „слиянию“ самих частиц. Это означает, что диффузионная подвижность приводит к процессам диффузионного роста наиболее выгодных по энергетическим соображениям частиц с холестерической структурой (так называемый механизм огрубления Лифшица-Слезова). Об этом свидетельствует образование доменов, в которых сохраняется текстура „отпечатков пальцев“, характерная для холестерических жидких кристаллов. Эффективность „слияния“ частиц и роста доменов зависит от температуры. Повышение температуры приводит к дальнейшему увеличению размеров холестерических доменов.

Увеличение концентрации ПЭГ в растворе $\left(C_{\text {Пэг }}>220 \mathrm{mg} / \mathrm{ml}\right)$ приводит к тому, что для таких дисперсий ДНК при комнатной температуре характерны спектры КД, не имеющие аномальной полосы (рис. 3, кривая 1). При этом результаты МУР для фаз ДНК, полученных в результате концентрирования частиц дисперсий в этих условиях, свидетельствуют в пользу нематикоподобного порядка с параллельной ориентацией молекул при их гексагональной упаковке в частицах этих дисперсий [32,33], что соответствует представлению об отсутствии аномальной оптической активности у таких фаз. 


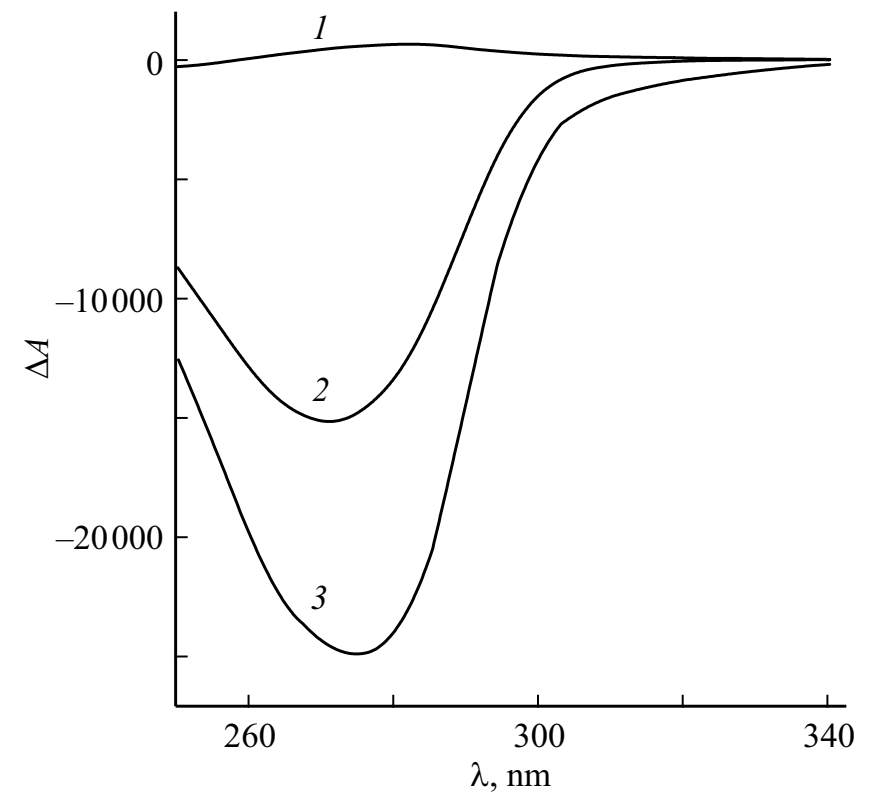

Рис. 3. Спектры КД исходной дисперсии ДНК, сформированной в водно-солевом растворе ПЭГ при $22^{\circ} \mathrm{C}(1)$, нагретой затем до $80^{\circ} \mathrm{C}(2)$, а затем охлажденной до комнатной температуры $22 \rightarrow 80 \rightarrow 22^{\circ} \mathrm{C}(3) . C_{\text {ПэГ }}=260 \mathrm{mg} / \mathrm{ml}$, $C_{\text {днк }}=30 \mu \mathrm{g} / \mathrm{ml}, 0.3 \mathrm{M} \mathrm{NaCl}+0.002 \mathrm{M} \mathrm{Na}^{+}$-фосфатный буфер, $\Delta A=\left(A_{L}-A_{R}\right) \cdot 10^{-6}$ optical units, $L=1 \mathrm{~cm}$.

Таким образом, при комнатной температуре для фаз, образующихся при концентрациях ПЭГ, превышающих $220 \mathrm{mg} / \mathrm{ml}$, т.е. в условиях, при которых результаты МУР предсказывают существование гексагональной упаковки ДЦ молекул ДНК [32], аномальная оптическая активность у частиц дисперсий не должна наблюдаться. Однако увеличение температуры водно-солевых растворов ПЭГ (при концентрациях ПЭГ больше $220 \mathrm{mg} / \mathrm{ml}$ ) сопровождается необычным эффектом: у частиц дисперсии ДНК, первоначально не имевшей аномальной полосы в спектре КД (рис. 3, кривая $1 ; 22^{\circ} \mathrm{C}$ ), такая полоса появляется (рис. 3, кривая $2 ; 80^{\circ} \mathrm{C}$ ). Рисунок 3 показывает также, что уменьшение температуры до комнатной приводит к дополнительному росту амплитуды аномальной полосы у частиц этой дисперсии (рис. 3, кривая $3 ; 22 \rightarrow 80 \rightarrow 22^{\circ} \mathrm{C}$ ).

Поскольку аномальная полоса в спектре КД является доказательством холестерической упаковки молекул ДНК в частицах дисперсии, можно утверждать, что ее появление у частиц, сформированных при СПЭГ от 220 до $300 \mathrm{mg} / \mathrm{ml}$, отражает возвращение от исходной гексагональной к холестерической упаковке молекул ДНК. Таким образом, зарегистрирован фазовый переход гексагональная $\rightarrow$ „возвратная“ холестерическая упаковка молекул ДНК в единичных частицах дисперсий [32].

Объяснение этого нового явления основано на учете ряда фактов. Очевидно, что максимальная плотность упаковки молекул ДНК в частицах дисперсии достигается при их гексагональной упаковке (при $C_{\text {Пэг }}$ от
220 до $320 \mathrm{mg} / \mathrm{ml}$ среднее расстояние между молекулами ДНК составляет от 2.8 до $2.4 \mathrm{~nm}$ ). При увеличении температуры диффузионная подвижность молекул ДНК в частицах с гексагональной упаковкой увеличивается, гексагональная структура становится нестабильной и должен произойти переход молекул ДНК в изотропное состояние. Этот переход происходит при достижении некоторой критической температуры, когда амплитуда смещений соседних молекул ДНК в единичных частицах дисперсии достигает порогового значения (порядка нескольких процентов от среднего расстояния между молекулами согласно известному критерию плавления Линдемана). При этом при высоком осмотическом давлении раствора ПЭГ переход молекул ДНК в изотропное состояние невозможен по стерическим причинам [41,42] и вместо плавления гексагональной структуры может произойти другой фазовый переход. При высоком осмотическом давлении раствора и высокой температуре за счет выигрыша в ориентационной энергии кручения Франка становится наиболее выгодной спирально закрученная структура. Поэтому при повышении температуры раствора происходит превращение энтропийно менее выгодной гексагональной упаковки в единичных частицах дисперсии ДНК в „возвратную“ холестерическую.
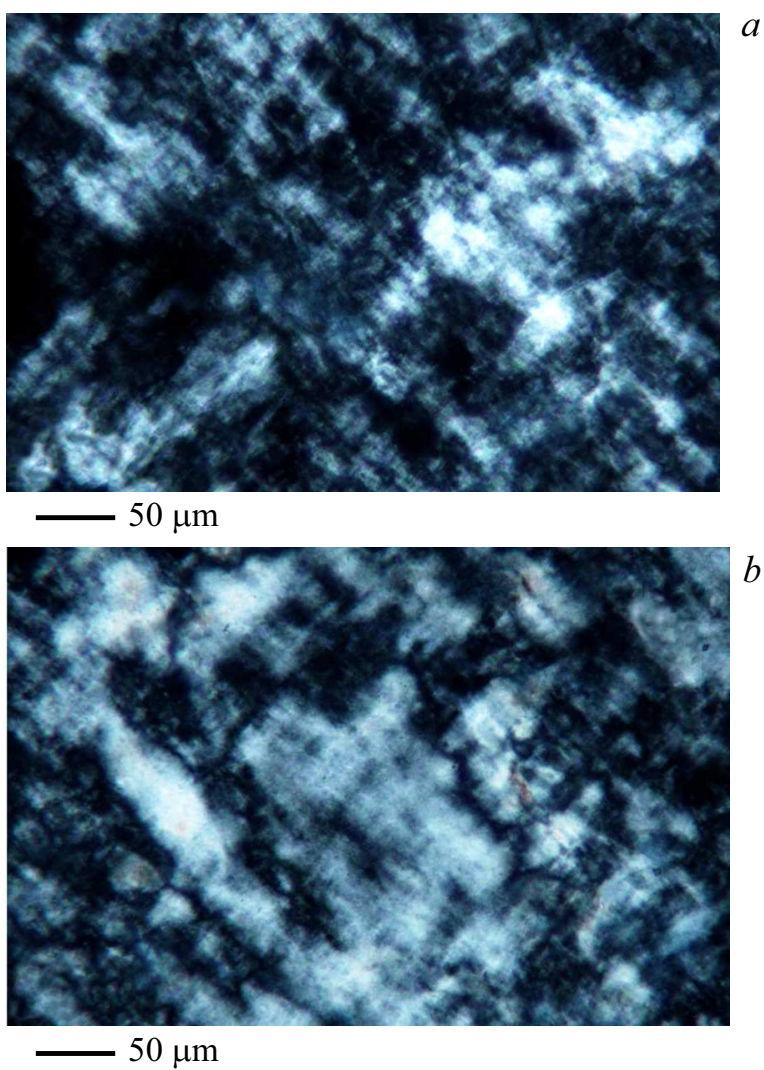

Pис. 4. Оптическая текстура тонкого слоя фазы ДНК, полученной в результате низкоскоростного центрифугирования частиц дисперсии ДНК, сформированной в ПЭГ-содержащем водно-солевом растворе $\left(C_{\text {Пэг }}=260 \mathrm{mg} / \mathrm{ml}\right)$ при 22 (a) и $60^{\circ} \mathrm{C}(b)$. Масштабная метка на рисунке соответствует $50 \mu \mathrm{m}$. 
Аномальная оптическая активность „возвратной“ холестерической структуры может отличаться от активности стандартного холестерика ДНК.

Полученные результаты могут быть объяснены с учетом концепции о существовании в частицах дисперсий ДНК ориентационно упорядоченных квазинематических слоев и их параллельном расположении в гексагональной структуре. Слои могут при увеличении температуры поворачиваться друг относительно друга, что приводит к формированию холестерической структуры. В единичных частицах дисперсий ДНК, полученных при фазовом исключении этих молекул из растворов ПЭГ, способ упаковки квазинематических слоев определяется не только осмотическим давлением раствора, но и его температурой.

На рис. 4 показана оптическая текстура тонкого слоя фазы, полученной в результате концентрирования (осаждения) частиц дисперсии ДНК, сформированной в водно-солевом растворе при $C_{\text {Пэг }}=260 \mathrm{mg} / \mathrm{ml}$. При комнатной температуре (рис. $4, a$ ) текстура не соответствует известным текстурам фаз ДНК $[12,13]$. В противоположность текстуре, показанной на рис. 2, эта текстура не содержит никаких признаков холестериков, однако в ней присутствуют анизотропные домены, наблюдаемые только в поляризованном свете (николи скрещены), но невидимые при обычном свете. При комнатной температуре число таких доменов мало, но с ростом температуры оно растет (рис. 4, $b$ ). Следовательно, текстура фазы, полученной при концентрировании независимых частиц дисперсии ДНК, не обнаруживает при нагревании никаких признаков появления „возвратной“ холестерической фазы.

Мы предполагаем два альтернативных объяснения наблюдаемого эффекта.

1. Дело в том, что изолированные (единичные) частицы дисперсии ДНК имели гексагональную плотную упаковку при комнатной температуре. В результате осаждения образуется фаза с высокой концентрацией частиц, которые имеют более или менее беспорядочную ориентацию в пространстве. Поэтому возникает сильное взаимодействие между по-разному ориентированным соседними частицами дисперсии с гексагональной упаковкой молекул ДНК, которое отсутствует в случае единичных частиц дисперсии. Это взаимодействие в сочетании с высокой плотностью упаковки молекул ДНК в частицах подавляет спиральную закрутку квазинематических слоев ДНК. В результате „слияния“ частиц с гексагональной упаковкой могут возникать анизотропные домены, в которых в среднем остается не закрученная структура квазинематических слоев ДНК, т.е. в этих условиях „возвратная“ холестерическая фаза не образуется.

2. Наличие и эволюция анизотропных областей (рис. 4) в сочетании с отсутствием текстуры „отпечатков пальцев“ может означать, что спиральный шаг возможной .возвратной. холестерической фазы, которая все-таки возникает при повышении температуры дисперсий ДНК при высоких концентрациях ПЭГ, может быть существенно меньше шага „классического“ холестерика ДНК.

Действительно, согласно результатам теоретически расчетов [32], высокому значению аномальной полосы в спектре КД, наблюдаемой в случае частиц „возвратной“ холестерической фазы (рис. 3, кривая 2) должен соответствовать шаг менее $500 \mathrm{~nm}$. Однако такой шаг не может быть обнаружен при помощи поляризационного микроскопа. Определение, какой именно из этих механизмов играет доминирующую роль в оптических свойствах текстур фаз, образованных при большом осмотическом давлении раствора ПЭГ, требует отдельного исследования и выходит за рамки настоящей работы. Следовательно, способ упорядочения молекул ДНК в единичных частицах дисперсий, образующихся в водносолевых растворах ПЭГ, может отличаться от способа упаковки этих молекул в макроскопических фазах.

\section{Выводы}

Получены ЖК дисперсии, сформированные в результате фазового исключения ДЦ молекул ДНК из водносолевых растворов ПЭГ. Изучены спектры КД этих дисперсий в интервале температур от 22 до $80^{\circ} \mathrm{C}$.

Получены ЖК фазы ДНК и изучены текстуры тонких слоев этих фаз.

Показано, что прямая корреляция между оптической текстурой макроскопической фазы ДНК, доказывающая ее структурную организацию, и способ упаковки этих молекул в единичных частицах дисперсий может не всегда соблюдаться. Высказаны соображения о возможных причинах этих различий.

Работа выполнена при поддержке Российского научного фонда (проект № 16-15-00041; Ю.М.Е., С.Г.С., В.И.С., O.H.K.)

\section{Список литературы}

[1] de Gennes P.-G. The Physics of Liquid Crystals. Oxford: Clarendon Press, 1974. 333 p. Перевод:де Жен П.Ж. Физика жидких кристаллов. М.: Мир, 1977. 400 с.

[2] Chandrasekhar S. Liquid Crystals. Cambridge: Cambridge University Press, 1977. 266 р. Перевод: Чандрасекар C. Жидкие кристаллы. М.: Мир, 1980. 344 с.

[3] Сонин А.С. Введение в физику жидких кристаллов. М.: Наука, 1983. $320 \mathrm{c}$.

[4] Капустин А.П. Экспериментальные исследования жидких кристаллов. М.: Наука, 1978. 368 с.

[5] Пикин C.A. Структурные превращения в жидких кристаллах. М.: Наука, 1981. 336 с.

[6] Liquid Crystalline Order in Polymers. NY:: Academic Press, 1978. 348 р. Перевод: Жидкокристаллический порядок в полимерах. М.: Мир, 1981. 352 с.

[7] Платэ Н.А., Шибаев В.П. Гребнеобразные полимеры и жидкие кристаллы. М.: Химия, 1980. 304 с.

[8] Bouligand Y. // Solid State Phys. Suppl. 14 - Liquid Crystals. N.Y.-London: Academic Press, 1978. P. 259-294. 
[9] Brown G., Wolken J. Liquid Crystals and Biological Structures. NY: Academic Press, 1979. 187 р. Перевод: Браун Г., Уолкен Дж. Жидкие кристаллы и биологические структуры. М.: Мир, 1982. 198 с.

[10] Livolant F. // J. Mol. Biol. 1991. V. 218. N 1. P. 165. doi 10.1016/0022-2836(91)90882-7

[11] Livolant F., Bouligand Y. // J. Phys. (France). 1986. V. 47. N 10. P. 1813. doi 10.1051/jphys:0198600470100181300

[12] Rill R.L., Strzelecka T.E., Davidson M.W., van Winkle D.H. // Phys. A. 1991. V. 176. N 1. P. 87. doi 10.1016/03784371(91)90435-F

[13] Livolant F., Leforestier A. // Prog. Polym. Sci. 1996. V. 21. N 6. P. 1115. doi 10.1016/S0079-6700(96)00016-0

[14] Robinson C. // Tetrahedron. 1961. V. 13. N 1-3. P. 219. doi 10.1016/S0040-4020(01)92215-X.

[15] Rill R.L., Hilliard P.R., Levy G.C. // J. Biol. Chem. 1983. V. 258. N 1. P. 250. PubMed ID 6848500

[16] Rill R.L. // Proc. Natl. Acad. Sci.USA. 1986. V. 83. N 2. P. 342. doi 10.1073/pnas.83.2.342

[17] Parsegian V.A., Rand R.P., Fuller N.L., Rau D.C. // Methods Enzymol. 1986. V. 127. P. 400. doi 10.1016/00766879(86)27032-9

[18] Podgornik R., Strey H.H., Rau D.C., Parsegian V.A. // Biophys. Chem. 1995. V. 57. N 1. P. 111. doi 10.1016/03014622(5)00058-6

[19] Yevdokimov Yu.M., Salyanov V.I., Semenov S.V. Skuridin S.G. DNA Liquid-Crystalline Dispersions and Nanoconstructions. Boca Raton: CRC Press (Taylor \& Francis Group), 2011. 304 р. Евдокимов Ю.М., Салянов В.И., Семенов С.В., Скуридин С.Г. Жидкокристаллические дисперсии и наноконструкции ДНК. М.: Радиотехника, 2008. 296 с.

[20] Hoang T.X., Giacometti A., Podgornik R., Nguyen N.T., Banavar J.R., Maritan A. // J. Chem. Phys. 2014. V. 140. N 6. P. 064902 . doi $10.1063 / 1.4863996$

[21] Onsager L. // Ann. NY Acad. Sci. 1949. V. 57. N 4. P. 627. doi 10.1111/j.1749-6632.1949.tb27296.x

[22] Livolant F. // J. Phys. (France). 1986. V. 47. N 9. P. 1605. doi 10.1051/jphys:019860047090160500.

[23] Livolant F. // J. Phys. (France). 1987. V. 48. N 6. P. 1051. doi 10.1051/jphys:019870048060105100

[24] Livolant F., Levelut A.M., Doucet J., Benoit J.P. // Nature. 1989. V. 339. N 6227. P. 724. doi 10.1038/339724a02739717

[25] Kassapidou K., Jesse W., van Dijk J.F., van der Maarel J.R. // Biopolymers. 1998. V. 46. N 1. P. 31. doi 10.1002/(SICI)1097282(199807)46:1<31::AID-BIP3>3.0.CO;2-Z

[26] Lerman L.S. // Proc. Natl. Acad. Sci. USA. 1971. V. 68. N 8. P. 1886. doi 10.1073/pnas.68.8.1886

[27] Evdokimov Yu.M., Platonov A.L., Tikhonenko A.S., Varshavsky Ya.M. // FEBS Lett. 1972. V. 23. N 2. P. 180. doi 10.1016/0014-5793(72)80335-1

[28] Yevdokimov Yu.M., Skuridin S.G., Lortkipanidze G.B. // Liquid Cryst. 1992. V. 12. N 1. P. 1. doi 10.1080/02678299208029034

[29] Goldar A., Thomson H., Seddon J.M. // J. Phys.: Condens. Matter. 2007. V. 20. N 3. P. 035102. doi 10.1088/09538984/20/03/035102

[30] Biswas N., Ichikawa M., Datta A., Sato Y.T., Yanagisawa M., Yoshikawa K. // Chem. Phys. Lett. 2012. V. 539-540. P. 157. doi 10.1016/j.cplett.2012.05.033

[31] Leonard M., Hong H., Easwar N., Strey H.H. // Polymer. 2001. V. 42. N 13. P. 5823. doi 10.1016/S00323861(00)00903-4
[32] Yevdokimov Yu.M., Skuridin S.G., Semenov S.V., Dadinova L.A., Salyanov V.I., Kats E.I. // J. Biol. Phys. 2017. V. 43. N 1. P. 45. doi 10.1007/s10867-016-9433-4

[33] Yasar S., Podgornik R., Valle-Orero J., Johnson M.R., Parsegian V.A. // Sci. Rep. 2014. V. 4. Article number 6877. doi 10.1038/srep06877

[34] Yevdokimov Yu.M., Salyanov V.I., Skuridin S.G., Semenov C.V., Kompanets O.N. The CD Spectra of DoubleStranded DNA Liquid Crystalline Dispersions. N.Y.: Nova Science Publishers, 2011. 103 p.

[35] Yevdokimov Yu.M., Skuridin S.G., Salyanov V.I., Muzipov E.R., Semenov S.V., Kats E.I. // Liq. Crist. Appl. 2018. V. 18. N 2. P. 81. doi 10.18083/LCAppl.2018.2.81

[36] Tunis-Schneider M.J.B., Maestre M.F. // J. Mol. Biol. 1970. V. 52. N 3. P. 521. doi 10.1016/0022-2836(70)90417-1

[37] Sackmann E., Voss J. // Chem. Phys. Lett. 1972. V. 14. N 4. P. 528. doi 10.1016/0009-2614(72)80256-2

[38] Saeva F.D., Sharpe P.E., Olin G.R. // J. Am. Chem. Soc. 1973. V. 95. N 23. P. 7656. doi 10.1021/ja00804a019

[39] Tinoko I., Bustamante C., Maestre M.F. // Ann. Rev. Biophys. Bioeng. 1980. V. 9. P. 107. doi 10.1146/annurev.bb.09.060180.000543

[40] Семенов С.В., Евдокимов Ю.М. // Биофизика. 2015. Т. 60. № 2. C. 242. Semenov S.V., Yevdokimov Yu.M. // Biophysics. V. 2015. 60. N 2. P. 242. doi 10.1134/S0006350915020177

[41] Grasso D., Fasone S., La Rosa C., Salyanov V. // Liquid Cryst. 1991. V. 9. N 2. P. 299. doi 10.1080/02678299108035507

[42] Grasso D., Gabriele-Campisi R., La Rosa C. // Thermochim. Acta. 1992. V. 199. N 1. P. 239. doi 10.1016/00406031(92)80268-2 